\title{
Towards Expressive Input for Character Dialogue in Digital Games
}

\author{
Nick Junius \\ University of California, Santa Cruz \\ Santa Cruz, California \\ njunius@ucsc.edu
}

\author{
Michael Mateas \\ University of California, Santa Cruz \\ Santa Cruz, California \\ michaelm@soe.ucsc.edu
}

\author{
Noah Wardrip-Fruin \\ University of California, Santa Cruz \\ Santa Cruz, California \\ nwardrip@ucsc.edu
}

\begin{abstract}
While there has been work in interactive narrative built using theory and practice from theater, it has mostly focused on the structure of narrative and how a player's interaction with the plot alters that structure. How a player interacts has usually been tied to common game interaction paradigms. There is an understanding that a videogame player exists somewhere between an audience member and a stage actor-but rarely are players allowed to express themselves in a manner similar to an actor. This paper argues that the acting and directing knowledge of theater is a potentially bountiful resource for designing player and NPC interactions. To illustrate this, the paper presents a literature review of theatrical methodology, its existing relationship to games, and a survey of projects in the interactive narrative and character interaction spaces. The chosen theater practices provide a useful basis for a new type of interaction between players and non-player characters. Additionally, particularly when looking at acting practices, their major concerns with the relationship between character and actor provide useful language to describe and further explore the relationship between the player and their avatar. Finally, this paper proposes one possible way of building systems to encourage new modes of play and alter the relationship between designers, systems, and players.
\end{abstract}

\section{CCS CONCEPTS}

- Computing methodologies $\rightarrow$ Model development and analysis; Modeling methodologies; Modeling and simulation;

\section{KEYWORDS}

Game Design, Interactive Narrative, Theater, System Design

\section{ACM Reference Format:}

Nick Junius, Michael Mateas, and Noah Wardrip-Fruin. 2019. Towards Expressive Input for Character Dialogue in Digital Games. In The Fourteenth International Conference on the Foundations of Digital Games (FDG '19), August 26-30, 2019, San Luis Obispo, CA, USA. ACM, New York, NY, USA, 11 pages. https://doi.org/10.1145/3337722.3337726

\footnotetext{
Permission to make digital or hard copies of all or part of this work for personal or classroom use is granted without fee provided that copies are not made or distributed for profit or commercial advantage and that copies bear this notice and the full citation on the first page. Copyrights for components of this work owned by others than the author(s) must be honored. Abstracting with credit is permitted. To copy otherwise, or republish, to post on servers or to redistribute to lists, requires prior specific permission and/or a fee. Request permissions from permissions@acm.org.

FDG '19, August 26-30, 2019, San Luis Obispo, CA, USA

(C) 2019 Copyright held by the owner/author(s). Publication rights licensed to ACM. ACM ISBN 978-1-4503-7217-6/19/08 ..\$15.00

https://doi.org/10.1145/3337722.3337726
}

\section{INTRODUCTION}

Real-time digital games commonly rely on non-player characters (NPCs) moving through space as a core part of gameplay, relying on these NPCs to interpret the player's actions and respond accordingly. When games featuring real-time, spatial gameplay want to have narrative moments, they frequently take away those very same spatial mechanics in favor of picking lines of dialogue in a dialogue tree and having the camera and characters (player and NPC alike) react according to the chosen line. While the graphical fidelity of what is presented has increased dramatically from Fallout [26] in 1997 to The Witcher 3 [28], Dragon Age: Inquisition [6], and Telltale Games' works in the past decade, what the player is being asked to do has changed little. In this way, even if the player has built their character from the ground up, they are moving between acting as their character (while walking around and in combat) and poking at their character's personality (while talking to NPCs).

Part of our focus on real-time gameplay is due to stage acting's real-time nature and our desire to get as close to that experience as possible. Additionally, in evaluating Façade's user interface, Sali et al found that players enjoyed the real-time, natural language understanding version of the game, in spite of the difficulties and systemic breakdowns they encountered, when compared to the more industry-standard menu options displaying full lines of dialogue or short abstract responses [32]. These findings, along with the game industry often falling back on dialogue trees, indicate there is a still under-explored space of digital game interfaces for character interaction.

When viewing the distinction between the spatial gameplay and dialogue trees, it was useful to categorize them as operating at the acting level and editing level respectively. Interacting at the acting level involves interacting in real-time with a playable model of some kind of character behavior, including combat and communication. Interacting at the editing level does not commonly involve a playable model or real-time interaction, though it may involve one of these elements (as Prom Week [24] does). As an example, "The Last Wish," a quest in The Witcher 3, involves the player fighting a djinn (a wish granting monster) and later, during a conversation, choosing whether or not Geralt and Yennefer should reaffirm their relationship. Fighting the djinn relies on the game's playable model of combat (the acting level) while the conversation between Geralt and Yennefer is a siloed, pre-authored dialogue tree (the editing level).

Even when games feature friendly NPCs, as Bioshock: Infinite [10] does, the player cannot interact with them at a similar level to their foes. While the player's primary companion, Elizabeth, might intelligently move and act based on where the player is looking at 
any given time [38], that is largely the extent of the free form, noncombat interactions. There are no verbs beyond walk and look the player has to interact with their companion, only the overloaded "interact with" button presses to begin little scripted vignettes. Still, having a character that understands their spatial relationship to the player for reasons other than combat is a very real step towards new kinds of gameplay.

In 2016, both Oxenfree [35] and Titanfall $2^{1}$ [7] allowed players to talk to characters while moving around their environments, in contrast to traditional interactive dialogue scenes. With that said, neither game placed much weight on what the player was doing while talking with other characters. They still rely on the player picking from a set number of choices and playing certain animations based on what the player picked. What they do provide is a step towards more real time interaction between players and NPCs as they naturally incorporate character silence rather than needing to add a timer or extra dialogue option. These two games still ask the player to operate as an actor and editor even as they ask that the player does both at the same time. Additionally, the interaction the player has with the game's plot is still very much at the editing level and whatever physical acting the player might try means nothing to the game's systems.

Theater provides a framework for translating spatial elements into narrative meaning. There have been repeated calls to look to theater for design inspiration [14] [17] [37], but specifically how actors and directors use human physicality and location in space to create emotional responses has largely been ignored. We posit that one possible starting point is using this theatrical knowledge as the basis for creating narrative nav-meshes, spatial markup and tagging to allow game systems, including NPCs, to interpret player actions at an acting and narrative level. We are interested in exploring character interactions more at the acting level, and more specifically using theater's knowledge of physicality and physical acting as the model. When we discuss physical acting with regards to player avatars in games, we are specifically referring to the affordances and actions available to the player, not that players must perform those actions in physical space as input.

We take this view of physical acting, in part, because of the lower technical burden of reading inputs using more traditional interfaces, such as the mouse and keyboard or Xbox 360 gamepads, compared to real world physical gestures. It also allows us to further explore the relationship between player and avatar as we attempt to create new types of interaction using these common interfaces. Furthermore, we seek to create a constrained environment that leverages players' existing experience with real-time, combat focused games to hopefully make communicative real-time gestures more accessible. Asking players to gesture using their own body removes some of those constraints and does not necessarily increase player engagement with characters-it may even make acting as another character more difficult [4]. For this reason we view work like Project IMMERSE [34] as falling beyond the scope of this paper.

Our goal with this paper is twofold. First, to provide an overview of some of the existing arguments that have been made about the relationship between theater and interactive narrative. Second, to

\footnotetext{
${ }^{1}$ These are not the first games to allow action to continue during dialogue. Starflight [36] allowed both the player and NPCs to use all their ship functions while in conversations, including firing weapons.
}

identify the most relevant insights from these theories, as well as theories and practices of physical acting, to inform a planned project (briefly described in the following subsection) that enables game players to engage in physical acting, using the bodies of their avatars, as the primary interactive component.

\subsection{System Design Goals}

When discussing plot and story, we specifically use Aristotle's definitions [1]. The story is made up of events the audience may or may not see. The plot is made up only of the events the audience experiences. For our purposes, these definitions are useful in describing the relationship between the full extent of the content authored, largely dialogue fragments (the story) and what any given playthrough will expose, the completed lines actually displayed (the plot).

In our planned project, the primary actions available to both the player and NPCs are moving through space and using a constrained set of gestures. In addition to the direction of movement, characters will necessarily need to be able to speed up or slow down their pace. To avoid overwhelming players with controls, we will limit the number of speeds to three, a default walk speed, a faster run, and a slower amble. This control over speed will extend to gestures, allowing players to dynamically change how quickly a gesture is done. Additionally, the length of time a gesture takes will be directly under the player's control. To reduce the authoring burden and avoid overwhelming the player, we will limit the number of core gestures to three.

By having the character gesture and move through space, values corresponding to the set of emotional affects that character is capable of expressing will be updated based on designer specified rules connecting gestures to emotional affects and the details interpreted by the narrative nav-mesh. Each of the emotional affects with the highest value will then be chosen and used as part of the conditions for picking the next line of dialogue.

In keeping with our goal of creating a simple interface and wanting to encourage more combinatorial play with movement and gesture, each player movement will change the values of multiple emotional affects. This means players will have to use sets of gestures and different kinds of movement to express specific sets of emotional affects rather than simply being able to hold a single button down and express exactly what they want all the time. We hope this will not only allow players to express characters as they desire, but also further highlight each character's physicality.

\section{THE CROSSOVER OF GAMES AND THEATER}

Aristotle has been one of the more influential guides for discussing the relationship between games and theater since Brenda Laurel's dissertation and subsequent publication of Computers as Theater [14] [17]. More recently there has been more interest in Konstantin Stanislavsky's acting methods as a lens for understanding interactive narrative [37] and as a game design methodology [16]. In this section we focus on how theater has influenced the current understanding of games and interactive drama as well as how our proposal for building systems inspired by theatrical acting and directing fits into this prior work. 
We have chosen to avoid discussing the work done applying Boal [9] and Brecht [33] to video games in significant detail in this section primarily because of our focus on the transformational properties of more traditional acting techniques [30] [15] [2]. For Boal's Forum Theater, the spect-actors ${ }^{2}$ would take turns playing the protagonist to explore how the protagonist's oppression could be broken [9]. In a sense, Boal's practice was more akin to the rehearsal described by more traditional theater practitioners [30] [15] [2] while we are more interested in what it means to be asking the player to be a more traditional type of actor during a performance.

Brecht's view of the character and actor as remaining distinct [33] is applicable to our interest in physical acting. However, at this point in our exploration of the subject, our primary concern is in better understanding the effects of attempting to capture the transformational properties of physical acting as a game interface. Additionally, with our definitions of the acting and editing levels of interaction, we view the switches between the acting and editing levels as implicitly Brechtian [33] in how they change the distance between player and character in a game like The Witcher 3 when transitioning from combat to dialogue scenes.

\subsection{Acting and Constraints}

One of the early observations Brenda Laurel makes in Computers as Theater is that simply placing an audience on stage is not a useful metaphor or practice for applying Aristotelean thinking about the theater to human computer interaction. She specifically states that by inviting the audience to interact with the the work, either theatrical or digital, they necessarily can no longer be considered audience members or observers, they must, by definition, be actors [14]. Following this assertion, Laurel says "Optimizing frequency, range, and significance in human choice-making will remain inadequate as long as we conceive of the human as sitting on the other side of some barrier, poking at the representation with a joystick or a mouse or a virtual hand" [14]. In other words, when we previously characterized the current standard of character interaction in digital games (the dialogue tree) as operating at the editing level, it is because the player can only prod the characters into acting, they are not in fact acting alongside the characters.

Another important observation Laurel makes is that the impreciseness of theater is a strength when looking to it for inspiration in interface design, particularly when designing interactive stories. Of particular note is her assertion that "when 'imprecision' works, it delivers a degree of success that is, in balance against the effort required to achieve it, an order of magnitude more rewarding than the precision of programming, at least for the non-programmer" [14]. Specifically with regards to games, designers don't always need to strive for perfect simulations or understanding of player intent. After all, misunderstandings and unintended consequences are a common cause of conflict and conflict is central to drama. Why shouldn't we embrace the conflict that emerges from the interaction of players and systems at a narrative level? By framing systems as characters, these breakdowns can actually make characters more believable and engaging [13].

\footnotetext{
${ }^{2}$ The audience members are participants, not simply passive observers in Theater of the Oppressed.
}

Laurel also reminds us that how a failure is presented is largely responsible for whether there is a breakdown in the experience [14]. A text parser not recognizing a word and simply stating that fact will not create a conflict useful to a plot. A character misinterpreting what the player said as flirting and then forcefully rejecting them is useful to a plot. Both of these are failures of a system to recognize player intent, but to create a useful conflict, an action, or at least a strong suggestion of action, should follow. Otherwise the player is asked to do the bulk of the work repairing the breakdown on their own.

In building interactive spaces, game designers must also be creating extrinsic and intrinsic ${ }^{3}$ constraints for interacting with the world. As Laurel observes: "the actor is constrained in the performance of [their] character primarily by the script and secondarily by the director, the accoutrements of the theater... and the performances of [their] fellow actors... In spite of these narrow limits, the actor still has ample latitude for individual creativity" [14]. Again this is why we do not usually consider a player's interactions with a dialogue tree as existing in the acting level. The constraints placed on the player rarely allow for creativity in expression or choice, rather they are simply expressing a preference of tone or character that already exists within the authored content. A combat encounter in F.E.A.R. [27] still has a massive number of explicit and implicit constraints placed on it, largely personified by nearly every button the player can press creating an attempt to cause physical harm. As Laurel describes "intrinsic constrains should not shrink people's perceived range of freedom of action, but rather enhance them" [14]. In this way the constraints in F.E.A.R. breed creativity in players in a similar way the constraints of a play script and production breed creativity in an actor.

\subsection{Aristotle and the Causes}

Aristotle has been the centerpiece of both Laurel and Mateas's work in interactive drama, with the Four Causes informing how player agency fits into traditional narrative structure. Formal cause, the structure created by the playwright (or designers), and material cause, what the audience experiences [17], have been given the most focus, with efficient cause, the material components that contributed to the production (including skills, tools and techniques), and end cause, the emotional experience of the audience [14], being less emphasized. Laurel does however observe that "the human interactor is also part of the efficient cause; that is, interactors are co-authors" [14] and this is one of our primary interests in building systems to facilitate digital acting. While actors may not have the agency of a character, they still have a large amount of agency in how a character is expressed and experienced.

In building the definition of interactive drama, Mateas incorporated Janet Murray's categories for the analysis of interactive story experiences: immersion (the feeling of being present and engaged in another place), agency (the feeling of empowerment from taking intentional action in the world), and transformation ${ }^{4}$ [17]. Of these

\footnotetext{
${ }^{3}$ Extrinsic constraints refer to the context of a person as an interactor, the placement of "pause" and "quit" buttons on a controller layout for example. Intrinsic constraints refer to the context of a person's ability to interact within the fictional world, whether they can pick up and throw a rock for example [14].

${ }^{4}$ Mateas identifies three distinct meanings of transformation: transformation as masquerade, or allowing players to become someone for the duration of the experience;
} 
three categories, he considers agency to be the most fundamental to creating an interactive drama, in part because he views immersion and transformation as already encapsulated in the Aristotelian model. His characterization of transformation, as a change in the protagonist, and additions to Aristotle's formal and material causes [17] explicitly position the player as a character in the world, not simply enacting a character, and to have a satisfying experience they must be able to affect the world as a character would.

Like Laurel's discussion of intrinsic constraints, Mateas's definition of agency in interactive drama relies heavily on how setting boundaries through material (constraints dictated by what the player can interact with) and formal (constraints dictated by plot and setting) affordances allows for a feeling of agency and creativity. He defines an experience creating a high amount of agency when the actions available to the player appear in concert with with what the plot, setting, and structure dictate and a lack of agency when there is an imbalance between the formal and material affordances [17]. In doing so he invokes Aristotle's idea of unity of action, or when actions in a plot all build towards some goal. It is for this reason we are specifically interested in acting and directing methodology since they provide fairly concrete ways of constraining the available actions for an actor in a natural way while still giving them agency over the character, scene, and plot.

In his discussion of immersion in relation to the neo-Aristotelian model of interactive drama, he re-frames it as usefully providing formal and material constraints for players. In particular, when talking about immersion, he mentions the usage of masks (as player avatars in games) as providing material and formal constraints for a player's actions [17], allowing them to better engage with the world Theater has long used masks and other devices to facilitate action on the stage, both for the audience and actors' benefit [30] and it's here where we are primarily interested in leveraging theatrical knowledge that remains largely untapped. Compared to masks, costumes, and puppets, a digital game character can provide many more intrinsic constraints and thus, by building interactive systems expressly using the same principles, we can more readily facilitate players acting as characters the way Mateas describes.

Mateas's reincorporation of transformation into his model of interactive drama provides a guide for the type of dialogue interface we are interested in. He states that there shouldn't be easily identifiable branch points and that possibilities should necessarily narrow as actions build up and force the plot in specific directions [17]. We are still interested in using the core of his explanation of this interactive dramatic structure as there are still currently very few experiences built with this in mind. However, rather than dialogue being the primary mode of interaction, the player's avatar's movements will inform the direction the conversation takes. In part, we want to further explore the player's relationship with their avatar and a new form of character interaction will be our starting point.

\subsection{Performing a Role}

In response to the focus on allowing players to shape plot in interactive narratives, Tanenbaum argues that participation in a story,

transformation as variety, or allowing players to explore facets of a theme from a variety of perspectives; and personal transformation, or facilitating players' self discovery. rather than interaction, is a way forward for creating interactive digital stories. He likens this participation to the constraints placed on actor in a scripted play and a type of bounded agency [37], similar to how Mateas views transformation as masquerade. Throughout the discussion of bounded agency, Tanenbaum cautions against seeing the player as a co-author, citing Laurel's ideas regarding intrinsic constraints [37]. While we find this warning useful, we feel it has the potential to be overly restrictive and minimizes the player's role in the efficient cause. We believe there is still space within the confines of bounded agency to allow the player some level of control over the plot, specifically by building narratives using Aristotle's distinction between plot and story, and his view of the playwright ${ }^{5}$ [1]. Mateas points to this when he says "each run-through of the story has a clean, unitary plot structure, but multiple run-throughs have different, unitary plot structures" when discussing a dramatic world with agency [17]. With this in mind, we can view the player as one of the constructors of the plot, within the story space the designer has created. It is still useful to view the player primarily as an actor in this type of experience, specifically to define how they interface with the world.

When discussing method acting, Tanenbaum notes that "not everyone who engages in an interactive story wants to be an author" [37]. What interests him is the transformative potential of method acting and how that transformation can make scripted lines feel spontaneous and concludes that "acting is a process that uses external perceptions and actions to transform the internal state of the actor" [37]. In light of the inherent challenges that come with acting, our goal is to provide an interface to facilitate a similar experience to acting but is constrained enough to keep attention on the dramatic action, not in the difficulty of acting. We believe limiting the player to consistent physical actions and interpreting those actions to drive the dialogue (and narrative progress) will avoid some of the problem of gating plot behind seemingly arbitrary challenges [29]. We do not want to force everyone interacting with this type of dialogue system to have to be an actor. Rather we are happy to give players a set of tools to get an idea of what the character they are playing is like. We want the mask their avatar represents to be as easy as possible to put on.

Tanenbaum and Mateas, as we discussed briefly in the previous section, find the theatrical practices of masks as a useful lens to view player avatars and, more broadly, to create a focal point for the intrinsic constraints placed on the player. Tanenbaum says "we can imagine a player's avatar as a form of Mask with a set of powerful character associations built into it" [37] and one current example to draw from is the Street Fighter series. Street Fighter might not be a narrative game in the traditional sense but every character's set of moves is both an expression of their character and a set of constraints both extrinsic and intrinsic. From the original release of Street Fighter II [3] onwards, Ryu and Guile have shared similar moves (they both can throw projectiles and have powerful, high risk uppercuts) but the differences in how the player performs these moves translate to noticeably different playstyles. Guile must hold a direction (back for projectiles and down for uppercuts) for a second or two (depending on the game) before pressing a button for a move

${ }^{5}$ Aristotle viewed it as the playwright's job to pick and order events rather than fabricate the stories those events are drawn from [1]. 
to register. Ryu needs to perform a quick series of directional inputs before pressing a button for a move to register. When playing either character, the player will develop the sense that Guile is someone who needs to plan and focus for more powerful attacks while Ryu is more willing to rely on his reflexes. With this in mind, while we don't want to replicate the special moves system found in Street Fighter (and numerous other games in the genre) we do find their connections to masks and physical acting affirming in our desire to use character movement as players' primary interface with a plot. ${ }^{6}$

If we want to follow the promise presented by Laurel's belief that bringing the audience into the experience makes them actors, then we need to be building systems around constraints of performance of character in the same way we build systems around combat and navigation of space. Noticeably absent from much of the work done applying theater to games is theatrical direction, where many of the decisions about the use of space and physicality reside. This is why we view the player as only one of the authors of the plot in our proposed approach. It is up to the game itself, through a system heavily informed by directing and acting methods discussed in the following section, to interpret the player's actions and add to the plot based on that interpretation and available story content.

\section{THEATRICAL THEORY AND PRACTICES}

In this section we look to an interpretation of the Stanislavsky method, elements of Japanese $N \bar{o}$ theater, and the Viewpoints practices as a basis for constructing a set of player actions and a model of interpretation. We picked these techniques specifically because they are practices used in training actors and directors in addition to being incorporated into the rehearsal process. We want to be clear, we are not saying these are the only ways to facilitate the type of physical acting we are trying to create. There is far too much written on physical acting to be comprehensively incorporated into this paper and the practices we discuss below were the ones we felt fit our goals the best. We should also note that these practices focus on training humans to act in physical space themselves. Because of this, given that we are building a digital system, our interest rests more in how these different techniques convey emotion-though the specifics of how they facilitate the internal transformation of actors are still useful to consider for exploring the relationship between player and avatar.

In attempting to create the outline of a digital model of physical performance, we are not attempting to capture and encode a single model and philosophy. Instead, and in concert with the intrinsic constraints we seek to create, we believe drawing from different traditions will allow us to construct a model reflective of our desire to mold dialogue around player actions.

\subsection{Stanislavsky and Energy}

Stanislavsky's method is one of the foundations of modern, naturalistic acting and though his work was indeed published, the changes he made towards the end of his life were instead primarily passed down through the Moscow Art Theater Studio Theater School and the State Institutes of Theater Art in Moscow and St. Petersburg. What Stanislavsky left behind would evolve into the Method of

${ }^{6}$ Elemental Flow [11] is a conversation based role-playing game currently in development also drawing inspiration from fighting games.
Physical Actions. This evolution would emphasize each actor's relationship to everyone else on stage as action was performed, further strengthening Stanislavsky's view of stage action as being born from disagreement, conflict, or struggle between people [15]. This definition of action allows us to further embrace Laurel's view of the impreciseness of drama [14] and more easily embrace a system's failure to properly interpret the player's actions as a source of conflict. In this way, we want to treat the interpretation system itself as part of our digital stage and as a partner for a player to play off of.

Another component of stage action for Stanislavsky is that the conflict generating the stage action must come from somewhere within the world of the play and be directed towards a partner. Whichever character initiates a conflict is considered the leading character of that action. For Stanislavsky, there are only two possible relationships between characters engaged in a conflict. Either the leading character is attempting to impose their view onto another character or they are making an observation about their "opponent" [15]. While much of the mechanics of what Stanislavsky describes here in regards to conflict is more applicable to how dialogue is authored for our proposed model, the concept of the leading character fits well with our goal of building dynamic conflicts in a plot. By having the model consider a new leading character after every action, the player will not always be the one in control of the direction of an action. With this, we hope to achieve the unique, unitary plot structures Mateas describes [17] with the addition of failures of the model to always interpret player intent correctly being a source of action.

When actually, physically performing a role, Stanislavsky refers to the concrete, external performance of a stage action as an actor's adjustment. He describes the particular arrangement of adjustments, defined in a production's rehearsal to be repeated each show, as part of the mise-en-scéne, the arrangement of scenery and stage properties in a play. Crucially he notes that it is impossible to predict exactly what an actor will do within the constraints of the mise-enscéne and that an actor's adjustments should never become fixed and repeated [15]. This is of particular importance to us as we want to build enough constraints into our model to allow players a range of physical expression without relying on something as discrete as the move inputs in Street Fighter. We are still constrained by making a digital system and, to reduce the complexity of the interface, we necessarily limit the number of gestures available to the player and rely on some number of authored animations rather than ask the player to construct complete gestures entirely on their own.

Important to Stanislavsky's view of physicality is the concept that each action is performed with some amount of energy and that actors' external movements should be preceded by an internal movement. He likened this internal movement to controlling a ball of mercury and that an actor's body should be reacting to where the actor wills the ball. Additionally, he makes sure to note that this direction of energy should not only be contained within an actor's body but flow out as an extension of their will. With energy, like with conflict, containing it within a single actor or character is not enough. To create a stage action, energy must be directed at a partner and the direction of energy towards a less than willing 
partner is a dispatch of energy with impediment. ${ }^{7}$ Of note is the two forms the impediment can take. First, an actor can restrain energy that wants to be directed at their partner. Second, an actor can direct energy at their partner to push them away [15]. We view this concept of energy as fundamental to building the library of gestures for players to use, particularly because it allows for much more readable expressions of player intent than purely relying on a model of movement through space. Additionally, by basing the meaning of gestures on this definition of energy, the interpretation of a gesture can be deterministic in our simplification of physical acting, allowing players to more easily understand how the system views their adjustments without being overly prescriptive (as gesture is not the only element of picking a line of dialogue in our model).

This is one of our reasons for limiting the player to three distinct gestures. By default, a character will project energy, though with little force, towards other characters and willingly receive energy. The three gestures then correspond to Stanislavsky's description of energy flow between characters. One will represent the unimpeded flow of energy to bring the other character closer to the gesturing character's view or position. One will represent the projection of energy at a character to repel that character and close the gesturing character off. One will represent the restraint of energy towards another character to hide the gesturing character's feelings towards the other character.

With regard to objects on stage, Stanislavsky puts them in two categories, objects that bear a psychological load and objects that do not. Objects that bear a psychological load are explicitly tied to a character and help an actor explore that character's internal life and their relationship to other characters. Note that these objects do not have to belong to the character to have a psychological load. Objects that do not have some psychological importance are simply tools for actors to add to their performance [15]. In his description of the material affordances, Mateas notes the importance of objects for player action [17] and our interest in objects is much the same as his. We consider objects that bear a psychological load as modifiers to gestures of a character rather than being additive. They afford us a way of altering the energy system underlying gestures and the gestures themselves while still maintaining our limit of three available gestures. Similar to the concept of the leading character, Stanislavsky's two categories of objects create the possibility of more dynamic interactions between a player and NPC through the use of both types of objects, and even changing which objects carry psychological load on repeated playthroughs to allow for more transformational variety as Mateas describes [17].

While we do see Stanislavsky's concept of a character's superobjective, a volitional objective (an answer to the question "what do I want?") that must encompass all of a character's desires [15], as useful to building constraints for players, we believe it exists too much at the editing level for our purposes. Additionally, the Method of Physical Actions was a step away from this purely internal focus, which characterized much of the American interpretation of Stanislavsky's work [15], and more interested in how the external informs the internal (what actually interests us). This is also one of reasons for taking inspiration from Zeami's essays on Nō theater.

${ }^{7}$ This is in contrast to the unrestricted flow of energy characters can project.

\subsection{Zeami and $N \bar{o}$ Theater}

Zeami Motokiyo was the progenitor of Nō theater in Japan during the 14th and 15th century where he built his father's theatrical practices into a total experience, incorporating mime, dance, poetry, and song-a practice that has continued to present day. Zeami's essays we are drawing from were never intended for wide circulation and are primarily concerned with defining his views on how Nō should be practiced, both in the mechanics of the art itself and the complete commitment needed by an actor from the age of seven onwards [30]. Of course we aren't in the position of asking for this level of commitment from our players, but for Zeami, his art was a lifetime commitment-and his likening of the aesthetic effect of theater to a flower, and its ever changing nature, reflected this [30].

His metaphor is still useful for our purposes as one of his primary concerns, like Stanislavsky, is that performance must be alive, grow, and change with both the practitioner and the audience. One final note before we discuss some of his philosophy and practice: unlike Aristotle, Zeami was a practitioner of theater and as a result, he often makes note of how his teachings should be used in relation to an audience [30]. As we are making a digital game, and explicitly interested in Laurel's view that a player/interactor is an actor [14], this reminder of having an audience is useful since we do not want to build an experience that requires theatrical knowledge to be engaging, much like how Zeami thought it necessary to create an engaging experience regardless of an audience's understanding of $N \bar{o}$.

In describing role play, Zeami states that, in general, role play involves imitation, though the degree to which the imitation reflects reality depends on the station of the character being portrayed. He notes that it is not just movements that must be imitated but dress and how poorly considered costumes can undermine a performance. Additionally, when describing the role play associated with different roles, especially of women and old men, he emphasizes the importance of conveying grace, as well as character, through physical movements. Regarding his description of how an old man should be played, he likens the movements to capturing the same beauty as an old tree still blossoming [30]. For Zeami, physical action was about conveying both the physical and internal truth of a role, though in a significantly more stylized way than Stanislavsky, and it is this approach to stylization that we want to use to inform the actual gestures players perform. Stylization can help make gestures more clearly read as a particular affect and more easily surface some of a character's internal feelings, making it easier for players to understand their character in the moment [2]. Additionally, Zeami's view of the importance of looking the part, not just acting the part, strongly parallels Laurel's view of intrinsic constraints creating an explorable space of action, a guiding principle for us when creating our characters' physical appearances.

Similar to Stanislavsky's view that all stage action must come from the text of a play, Zeami sees all movement as necessarily being informed by the words chanted on stage or, "communicate first by hearing, then by sight." In his example of an actor portraying a character weeping on stage, Zeami notes how if the gesture of raising a sleeve to the face precedes the concept of weeping, the words will seem out of place and the totality of the moment is reduced. More broadly he states how a person's intentions give 
way to their behavior and that by informing movement on stage with the words of a play, the action will feel natural [30]. This is a much finer grain view than Stanislavsky's volitional objectives and informs us of another utility we must write into characters' lines: a suggestion of action. Though we are picking the next lines of dialogue based on what the player does, those lines should help guide a player in some way towards further stage action to keep them continuously engaged in how a scene plays out.

When describing the necessary novelty of performance, Zeami emphasizes the need for an actor to continue to find new ways of performing the same gesture to, if nothing else, continue to refine their art. He also notes that even if there aren't visible external changes to the performance, the audience will pick up on the novelty the actor has found. It is from this novelty of performance Zeami sees the transformative potential of acting and in his example, how an actor can move from imitating an old man to becoming one [30]. For our model, and since we are interested in having the player help construct the plot, Zeami's view of the power of transformation for an actor is very much what Tanenbaum describes as a way forward for interactive narrative. By giving the player control of their adjustments at all times, they will be able to find the novelty Zeami describes even if they find themselves in a plot they've already experienced.

Zeami likened what the audience sees of an actor on stage to a marionette and the actor's presence and intensity of mind to the strings controlling the puppet [30]. By turning the audience into an actor, in one sense we are expressly going against his belief that the audience should never see the puppet's strings. In another sense his metaphor is useful to us in how it ties back to the transformational pleasure of becoming another character. For us, it is the player's job to breathe life into their character and become that character through the interface we build. We may be asking the player to use the strings Zeami describes, but if we can make the strings disappear and facilitate the player feeling as though they are acting, we will have succeeded both in creating a new type of dialogue system and keeping the audience unaware of the puppet's strings.

\subsection{The Viewpoints}

The Viewpoints approach to movement and staging was born out of the 1960s and 70s and a desire to question everything about traditional performance techniques. It was partially a reaction to the internal focus of the American interpretation of Stanislavsky's work. Born from innovations in dance and choreography, the Viewpoints turned the source of movement inward and expressly professed that whatever movements came from this shift in perspective was the art itself or, "what made the final dance was the context of the dance" [2]. Viewpoints, much like Zeami and Stanislavsky, sees the process of performance as integral to the final product. This perspective is integral to our approach to plot as being a collaboration between the player, designer, and game system. Additionally, it provides another description of Mateas's view of the transformational variety of interactive drama and the value of such variety.

Anne Bogart an Tina Landau define the Viewpoints as:

- "A philosophy translated into a technique for (1) training performers; (2) building ensemble; and (3) creating movement for the stage" [2].
- "A set of names given to certain principles of movement through time and space; these names constitute a language for talking about what happens on stage" [2].

- "Points of awareness a performer or creator makes use of while working" [2].

They also use nine Physical Viewpoints, separated into Viewpoints of Time and Viewpoints of Space, rather than the Six Viewpoints developed by Mary Overlie [2]. These Physical Viewpoints are our primary basis for interpreting a character's movement through space to build a narrative nav-mesh as well as informing contextual actions related to the playable space. Bogart and Landau also developed Viewpoints for voice, but the incorporation of voice is beyond the scope of our model for now. What follows is a discussion of the nine Physical Viewpoints.

3.3.1 The Viewpoints of Time. These include tempo, the rate of speed at which movement occurs; duration, how long a sequence of movement continues, specifically how long a group of people stay inside a certain section of movement; kinesthetic response, the impulsive movement that occurs from a stimulation of the senses; repetition, repeating a movement within your own body or repeating the shape, tempo, gesture, etc. of something outside your own body [2].

For our model, these Viewpoints primarily inform the development of the interface between player and character. We seek to give players as much control as possible over their character's movements and gestures, within the constraints of purely digital input. We particularly want to allow players to explore tempo and duration, with the gestures we create for characters, by allowing them to choose how quickly to perform and how long to hold particular poses. We cannot capture the granularity of what these Viewpoints are capable of in physical space, in part to avoid overwhelming players with options, but we feel that by providing players a constrained version (the distinct default, run, and slow walks described in Section 1.1) we will allow them to experience a similar type of expressiveness in a much shorter amount of time.

3.3.2 The Viewpoints of Space. These include shape, the outline the body (or bodies) makes in space made up of lines, curves, or some combination. Additionally the shape can either be stationary or moving and can take one of the following forms: the body in space, the body in relation to architecture, the body in relation to other bodies; gesture, shape with a beginning, middle, and end and broken into behavioral gestures ${ }^{8}$ and expressive gestures ${ }^{9}$; architecture, the physical environment and its effects on physical movement to create spatial metaphors ${ }^{10}$; spatial relationship, the distance between things on stage especially one body to another, one body (or bodies) to a group of bodies, and the body with architecture. Additionally there is an emphasis placed on extremes of distance and the expressiveness of changes in distance; topography, the landscape, floor pattern, and design of a space as characterized by movement through it [2].

These Viewpoints are the primary basis for the creation of a narrative nav-mesh, with particular attention paid to architecture and

\footnotetext{
${ }^{8}$ These are observable behaviors in everyday reality. [2]

${ }^{9}$ These are abstract and symbolic gestures aimed at representing an internal truth. [2] ${ }^{10}$ The process of giving form to feelings like "I'm trapped" or "I'm up against the wall." [2]
} 
topography. Topography especially can allow us to create spaces that change the way a player's character is able to move, allowing them to directly feel their character's reactions to the environment and choose how to play with that reaction. By building a model grounded in the shapes created by the position of players in their environment and relative other characters, we can begin to interpret player movement through space in a constructive way and use that interpretation to pick appropriate lines of dialogue.

3.3.3 Soft Focus. This is described as the physical state where the eyes relax and take in more than simply one or two things in sharp focus. A primary goal of soft focus is to allow a person to look at their surroundings and other people without desire. In the physical space, this is primarily to allow actors to have a more holistic view of the space they inhabit and connections to everything happening on stage [2]. For our purposes this concept is useful for two reasons. First, we want players to do more than stand in front of other characters to interact with them, encouraging them to move through the environment, either through dialogue or the design of the space itself. Second, as players are not in direct control of what their character says, their relationship to other characters will not be purely transactional since the other characters are the core of the experience not simply a means to an end.

Bogart and Landau explicitly position the Viewpoints as a collaborative approach to performance with the goal of, to return to Laurel's intrinsic constraints, giving performers the freedom to explore all possibilities within a space [2]. Noteworthy for our purposes is that all of those possibilities represent a valid approach to the performance [2]. Therefore all the actions our interface enables must allow player expression to the game system to be used in the construction of the plot in some capacity. Beyond this, there are significantly more details about the Viewpoints than we can include, the bulk of which are about the specifics of their practice and incorporation into the rehearsal process.

We should note that we are not the first to attempt to create a computational system inspired by the Viewpoints. The Viewpoints AI project [12] sought to create a gesture recognition system using physical gesture. Unlike the system we are proposing, the Viewpoints AI utilized Microsoft's Kinect as its source of input and used Bogart and Landau's ideas as a way to translate the player's performance in physical space into something understandable by a virtual character. As we have already stated, we are not building a system to recognize physical gestures from players' bodies, rather, we are using the Viewpoints to guide our design of player actions, both by having these actions always be interpreted meaningfully by the system and through our decisions of which viewpoints to put directly under the player's control and which are concerns more for content authoring.

\section{EXISTING GAME CASE STUDIES}

In this section we will briefly look at various games to come out of the interactive narrative space and how their gameplay relates to our discussion of theater's usage of physicality and space as well as plot and story structure. Not all of the games in this section are interactive dramas or even explicitly interactive narratives but each game's focus is the interaction between characters, even if the player does not have an avatar.

\subsection{Façade}

Mateas and Stern's Façade [19] is explicitly an interactive drama and focused extensively on implementing the neo-Aristotelian model of drama Mateas outlined [17]. Integral to the interaction model was the concept of discourse acts, actions the player expressed through dialogue with the characters using a text parser, rather than the physical acts of firing a gun or obstacle avoidance [20]. Additionally, the two NPCs present, Grace and Trip, interpret the player's lines through abstract social games. These include the affinity game, responsible for determining whose side the player is taking; the hotbutton game, responsible for surfacing incendiary topics, exposing character backstory, and updating the affinity game; the therapy game, responsible for updating Grace and Trip's self-realization about their problems [20].

Much of the structure of Façade is rooted in the concept of beats, primarily to afford a level of autonomy to the characters within the plot [18]. Due to beats having an underlying canonical structure [20], we can characterize the drama manager in Façade as reconstructing the plot to fit reasonably well with whatever the player does. Additionally, Façade selects new beats to add to the plot based, in part, on an Aristotelian tension arc [20].

When outlining Façade, Mateas pointed to the importance of embodied interactions, including moving through the environment, interacting with objects, and physical contact with characters [17]. In the final experience, these are implemented but not foregrounded to the same degree as the player typing dialogue. Compared to our discussion of physicality in theater, Façade is light on those elements though it still exists at the acting level because the game treats the player first as a character in the world and expects them to infer the effect of their behavior through a playable model [20]. The way Façade uses its real-time playable model of character dialogue to redirect the plot is a major inspiration for our proposed relationship between player movement and character dialogue.

For our proposed interface, we want to provide the player with something more constrained than the free form text input of Façade, in part to avoid unproductive misinterpretations of input. With that in mind, we still want to build an expressive space of player driven gesture-and use the more constrained space to enable players to more easily understand the rules governing their interactions than some of the abstracted games in Façade would allow [20].

\subsection{Prom Week}

Unlike the other games in this section, Prom Week is a social interaction game where the player is not a character and exists more as the narrative causality driving certain characters. Integral to Prom Week's design was the concept of a "social physics engine," invoking the emergent properties of physics simulation in many modern games [22] (and similar to what we discussed in Section 2.1). The primary point of interaction a player has in the game is choosing what social action a character should take, chosen from a list organized by characters' desires [23]. Characters' desires are determined by the social considerations created by the underlying social network [23]. Once an action is chosen for a character, it is up to the other character to decide whether to accept or reject the intent behind the action (like being asked out on a date) [21]. Though Prom Week bases its social exchanges between characters 
on Goffman's dramaturgical analysis and Berne's psychological games, these actions' focus on characters changing their relationships [23] in fact creates the same type of stage action Stanislavsky describes.

The player's relationship to Prom Week and all of its characters exists at the editing level even though there is an underlying playable model of social interaction. This is because of the game's turn-based nature. That said, the game does allow for creative, combinatorial approaches to character action through the creation of a story world without explicit connections between actions and world states [23]. Additionally, while the characters do play stylized animations ${ }^{11}$ in response to events, they are less character-specific than our goals for player controlled gestures and movement. Our main interest in Prom Week is its distillation of theories from the social sciences and observations from the operations of media into working, playable models in a digital game. Also important to us are the game's affordances for plot generation stemming from the variety of approaches to problem solving it allows [25]. While Prom Week is not expressly a story generator, that its primary concern was with characters' goals, not with a well structured plot, allows for a significant amount of transformational variety and player expression in the creation of a plot through a given scenario.

This variety in the plots through a given scenario was facilitated by Comme il Faut (CiF), the social system of Prom Week, and its decoupling of character, role, and action within the system [22]. Another important goal of $C i F$ was to reduce the burden of authoring social exchanges compared to the behaviors of Façade [22]. This modularity lends lends itself to our goal of building plots based on players' actions, incorporating the Viewpoints' emergent view of movement, and our observation of the potential transformational variety in Stanislavsky's concepts of leading characters and objects bearing psychological load.

\subsection{Versu}

Versu is an interactive drama built using autonomous characters constrained by social practices (recurring social situations) [8]. Characters' actions arise from their own beliefs and desires-rather than characters being forced into acting based on a drama manager [8]. Additionally, Versu decoupled social practices from characters and characters from roles, similar to what was done in Prom Week, to allow for significantly more possible variations within a story [8]. By making everything modular and simulation driven, one of Versu's goals, along with its button clicking interface, was to make the process of understanding the rules of the world easier, and thus allowing the player to act in a more informed way than in Façade [8]. With the type of interface we've been describing, we want to split the difference between Versu's explicit, always valid, set of choices and Façade's purposefully obfuscated underlying systems. As described in the section on the Viewpoints, we believe that everything the player can do should be valid to the simulation (as Versu does) though we also see the value in the hiding some of the details about the underlying system to further ground the player in the experience (as Façade does).

\footnotetext{
${ }^{11}$ Similar to the expressive gestures described in the Viewpoints.
}

What the player is physically doing in Versu is no different from our earlier characterization of dialogue trees and Prom Week's interaction, meaning the interface itself exists at the editing level. To return to Zeami's comparison of actors to puppets, Versu makes the existence of the strings controlling the puppet central to the experience. Though we want to create something more continuous and graphically focused than Versu, its autonomous approach to characters, along with its similarities to Prom Week, connect it to our view of plot construction, the emergent properties of movement according to the Viewpoints, and Stanislavsky's concept of the leading character. With this in mind, our proposed system falls somewhere between Prom Week and Versu at one end and Façade at the other. We want to keep the real time interactions and compositional elements of Façade but constrain the base actions available to the player to allow them to get a clearer understanding of the rules governing the interactions as described in Prom Week and Versu.

\subsection{La Dama Boba}

La Dama Boba is an adventure game adaptation of the Lope de Vega play of the same name designed help introduce high school students to theater and the specifics of the play [16]. The adaptation process was heavily influenced by the Americanized version of Stanislavsky's work [16] we discussed earlier. Once Manero et al had picked the player character, Laurencio (the male lead of the original play), they used Stanislavsky's concept of the superobjective for a single character to choose what needed to be cut from the script without breaking their leading character's plot line [16]. They then separated Laurencio's arc into separate milestones to then turn that section of the play into one of five adventure game challenges that made up the game's plot [16]. Each character was given an agenda to facilitate conflicts and engage the player through Stanislavsky's definition of stage action [16]. Additionally, the game was made non-linear as certain milestones were considered to be semi-independent and described as creating a performative space [16].

We find the usage of Stanislavsky's objectives interesting from an adaptation perspective but when looking at a playthrough of the finished game [5], the connection to Stanislavsky's methods are somewhat difficult to see and could be characterized as the TaleSpin Effect $^{12}$ [39] in relation to the design of a game rather than its processes. Some of this is due to the game explicitly being designed as an adventure game and within the constraints of adapting an existing play. In our view, the player's interactions with the game exist at the editing level because of its adherence to adventure game conventions, and thus lack of an underlying playable model, even modeling one of its challenges directly on the battle of wits in The Secret of Monkey Island [16]. Additionally, the description of the adaptation process is mostly concerned with the design-time writing of characters instead of how characters express themselves in the final artifact.

There are two instances where the game does allow the player to get closer to acting as their character rather than editing them. First, the player must complete a Redonilla ${ }^{13}[16]$ and is actually finishing sentences on the page. Second, the player must find and

\footnotetext{
${ }^{12}$ When the output of a process hides the underlying complexity of that process.

${ }^{13} \mathrm{~A}$ form of Spanish poetic composition [16].
} 
correct spelling errors in a poem [16], again on a page rather than simply telling the character what to do. In our view, the La Dama Boba game provides an example of the limitations of adapting novel design approaches within the constraints of existing game design paradigms.

\section{FUTURE WORK}

As mentioned throughout, we plan to build a complete, detailed digital model using the theory and practices presented. Our first steps will be to create a prototype of the energy and gesture system we described, to create part of the representation of character state to be used to retrieve a line of dialogue. After that we will begin building a small environment using the principles of the Viewpoints of Space to create a narrative nav-mesh and settle on a representation to describe the movement of a player through that space. Finally, we will combine the player-driven gestures and the interpreted movement into a content request usable by the searchable context-free grammar system Expressionist [31] to retrieve an appropriate line of dialogue to display.

\subsection{Partial Gesture System Description}

The gesture system we hope to build has four main steps in its interaction loop:

- The player pressing a button (or buttons).

- The player character performing a corresponding gesture.

- How the gesture was performed updating the values corresponding to emotional affects.

- The largest affect values being used to generate a line of dialogue.

The rules governing the translation of a button press into a character gesture are directly inspired by all three of the theater practices we discussed. Each gesture, beyond the default state, is labeled as one of Stanislavsky's energy states: open flow, closed flow, and projected energy. The animations a character performs when in each of those energy states is that character's physical interpretation of embodying that particular energy state. For example, a character who is usually open and honest about their feelings would have a more open stance towards the other character when performing the gesture corresponding to open flow and when performing the closed flow gesture would position themselves to literally be trying to keep everything they can close to their core, similar to how Zeami describes actors' movements conveying grace and character. Additionally the control the player is given over the tempo, duration, and repetition of each of the gestures comes directly from the Viewpoints of Time and contributes directly to the concept for the basic control scheme for the interface.

Each button corresponding to a gesture can be held for as long as the player wants, holding that gesture for the same time. By repeatedly holding and releasing the button, the player can repeat the full gesture as many times as they want. Similar to the gesture buttons, the tempo buttons can be held as long as a player desires and will increase or decrease the tempo of the performed gesture.

Translating the character's gesture into changes in emotional affect values is again inspired by all three of the theater practices we covered. This step in the interaction loop is analogous to the practices' insistence that physical movement reflect something about the internal state of the character and/or performer. Since we are giving the player direct control over the character's physicality, the way the character moves must have some effect on the kinds of emotional affects they are expressing. Each gesture can increase or decrease the value of each emotional affect the character can express. This update may result in possibly conflicting emotional affect values being raised by the same gesture. For example, if the closed flow gesture results in the character fidgeting in their seat, both the emotional affects of anxiety and joy could be raised at equivalent rates as both can be expressed by fidgeting. Slowing the fidgeting down might make joy's value rise faster than anxiety and speeding it up might have the opposite effect should the player want to have the character be more definite in the way they are expressing themselves.

Our desire to use Expressionist to generate the lines of dialogue corresponding to the emotional affects performed by a character is primarily due to the system's tagging interface. The tagging system allows us to directly use the set of emotional affects with the largest values as part of the rules to generate lines of dialogue and use the three theater practices' common belief that physicality needs to be grounded by a character's or performer's internal state. Additionally, this means that to close the loop of interaction, the dialogue generated is a reflection of the character's physical actions and will help the player decide if they want to continue performing the same gesture, reminiscent of Zeami's belief that words inform the way a gesture is read.

\section{CONCLUSION}

Our goal with this paper is to simultaneously provide a view of the existing relationship between theater, games, and interactive narrative and highlight parts of theater that are useful in understanding character interaction that have not been widely discussed. For this reason our focus was on production techniques rather than pure theory and how those techniques could be applied to digital games. Additionally we wanted to note how much of the existing work in interactive drama, resting heavily on Aristotle, arrived at conclusions regarding the player's relationship to their avatar and plot that had long been a concern of theater practitioners. Furthermore we feel these theater practitioners' specific views on an actors' relationships to characters provide more concrete foundations for interface and gameplay design than the heavily Aristotelian and theory focused leanings of existing work.

We hope that by showing the parallels between the heavily practical side of theater production and the view of a player as an actor, we will not only be able to create a novel game in the future using this work, but we will enable other game designers and academics to explore the player's role in games in new ways. Our interest in the intersection of games and theater is primarily rooted in the creation of new interactive dramas but we believe the lessons learned over theater's history are useful beyond the character interaction we have focused on.

\section{ACKNOWLEDGMENTS}

Thank you to Michael Chemers, Kimberly Jannarone, and Batu Aytemiz for with sources and Isaac Karth and Stella Mazeika for the time and feedback they generously provided. 


\section{REFERENCES}

[1] James Bierman. [n. d.]. Aristotle or Else. Retrieved Janary 7, 2019 from http://tragedy.ucsc.edu/

[2] Anne Bogart and Tina Landau. 2005. The Viewpoints Book: A Practical Guide to Viewpoints and Composition. Theatre Communications Group.

[3] Capcom. 1991. Street Fighter II: The World Warrior.

[4] Steven Dow, Manish Mehta, Ellie Harmon, Blair MacIntyre, and Michael Mateas. 2007. Presence and engagement in an interactive drama. In Proceedings of the SIGCHI conference on Human factors in computing systems. ACM, 1475-1484.

[5] eAdventureUCM. 2013. La Dama Boba (The Foolish Lady). El juego (The game). Retrieved Janary 8, 2019 from https://www.youtube.com/watch?v= $2 \mathrm{mqLyjKOn3c \& feature=youtube \_ gdata \_ player}$

[6] Bioware Edmonton. 2014. Dragon Age: Inquisition.

[7] Respawn Entertainment. 2016. Titanfall 2.

[8] Richard Evans and Emily Short. 2014. Versu - a Simulationist Storytelling System IEEE Transactions on Computational Intelligence and AI in Games 6, 2 (2014), 113-130.

[9] Gonzalo Frasca. 2001. Videogames of the oppressed: Videogames as a means for critical thinking and debate. Master's thesis. School of Literature, communication, and culture, Georgia Institute of Technology.

[10] Irrational Games. 2013. Bioshock Infinite.

[11] Tea-Powered Games. TBD. Elemental Flow.

[12] Mikhail Jacob, Alexander Zook, and Brian Magerko. 2013. Viewpoints AI: Procedurally Representing and Reasoning about Gestures.

[13] Rachel Lee Knickmeyer and Michael Mateas. 2005. Preliminary evaluation of the interactive drama facade. In CHI'05 Extended Abstracts on Human Factors in Computing Systems. ACM, 1549-1552.

[14] Brenda Laurel. 2013. Computers as Theater (2nd. ed.). Addison-Wesley Professional.

[15] Irina Levin and Igor Levin. 2002. The Stanislavsky Secret. Colorado: Meriwether Publishing.

[16] Borja Manero, Clara Fernández-Vara, and Baltasar Fernández-Manjón. 2013. Stanislavky's System as a Game Design Method: A Case Study.. In DiGRA Conference. Citeseer.

[17] Michael Mateas. 2001. A preliminary poetics for interactive drama and games. Digital Creativity 12, 3 (2001), 140-152.

[18] Michael Mateas and Andrew Stern. 2002. A behavior language for story-based believable agents. IEEE Intelligent Systems 17, 4 (2002), 39-47.

[19] Michael Mateas and Andrew Stern. 2005. Façade.

[20] Michael Mateas and Andrew Stern. 2005. Structuring Content in the Façade Interactive Drama Architecture.. In AIIDE. 93-98.

[21] Joshua McCoy and Michael Mateas. 2009. The Computation of Self in Everyday Life: A Dramaturgical Approach for Socially Competent Agents.. In AAAI Spring Symposium: Intelligent Narrative Technologies II. 75-82.

[22] Joshua McCoy, Michael Mateas, and Noah Wardrip-Fruin. 2009. Comme il faut: A system for simulating social games between autonomous characters. (2009).

[23] Josh McCoy, Mike Treanor, Ben Samuel, Brandon Tearse, Michael Mateas, and Noah Wardrip-Fruin. 2010. Authoring game-based interactive narrative using social games and comme il faut. In Proceedings of the 4th International Conference \& Festival of the Electronic Literature Organization: Archive \& Innovate. Citeseer.

[24] Josh McCoy, Mike Treanor, Ben Samuel, Noah Wardrip-Fruin, and Michael Mateas. 2012. Prom Week.

[25] Joshua Allen McCoy. 2012. All the World's A Stage: A Playable Model of Social Interaction Inspired by Dramaturgical Analysis. Ph.D. Dissertation. University of California, Santa Cruz, Santa Cruz, CA.

[26] Interplay Productions. 1997. Fallout: A Post Nuclear Role Playing Game.

[27] Monolith Productions. 2005. F.E.A.R. First Encounter Assault Recon.

[28] CD Projekt Red. 2015. The Witcher 3: Wild Hunt.

[29] Aaron A. Reed. 2017. Changeful Tales: Design-Driven Approaches Toward More Expressive Storygames. Ph.D. Dissertation. University of California, Santa Cruz, Santa Cruz, CA.

[30] J Thomas Rimer, Masakazu Yamazaki, et al. 1984. On the Art of the Nō Drama: The Major Treatises of Zeami; Translated by 7 . Thomas Rimer, Yamazaki Masakazu. Princeton University Press.

[31] James Ryan, Ethan Seither, Michael Mateas, and Noah Wardrip-Fruin. 2016. Expressionist: An authoring tool for in-game text generation. In International Conference on Interactive Digital Storytelling. Springer, 221-233.

[32] Serdar Sali, Noah Wardrip-Fruin, Steven Dow, Michael Mateas, Sri Kurniawan, Aaron A Reed, and Ronald Liu. 2010. Playing with words: from intuition to evaluation of game dialogue interfaces. In Proceedings of the Fifth International Conference on the Foundations of Digital Games. ACM, 179-186.

[33] Ben Samuel. 2016. Crafting Stories Through Play. Ph.D. Dissertation. University of California, Santa Cruz, Santa Cruz, CA.

[34] Daniel G Shapiro, Joshua McCoy, April Grow, Ben Samuel, Andrew Stern, Reid Swanson, Mike Treanor, and Michael Mateas. 2013. Creating Playable Social Experiences through Whole-Body Interaction with Virtual Characters.. In AIIDE.

[35] Night School Studio. 2016. Oxenfree.
[36] Binary Systems. 1986. Starflight.

[37] Joshua Tanenbaum. 2011. Being in the story: readerly pleasure, acting theory, and performing a role. In International Conference on Interactive Digital Storytelling. Springer, 55-66.

[38] Tommy Thompson. 2017. The AI of BioShock Infinite's Elizabeth | AI and Games. Retrieved Janary 8, 2019 from https://aiandgames.com/ bioshock-infinite-elizabeth/

[39] Noah Wardrip-Fruin. 2009. Expressive Processing: Digital fictions, computer games, and software studies. MIT press. 